\title{
The Effectiveness of Primary Teacher Training Programmes in Meeting the Needs of Pupils with Special Needs In Inclusive Settings In Masvingo
}

\author{
Loveness Chindanya \\ Great Zimbabwe University
}

\begin{abstract}
A study was conducted to investigate the effectiveness of primary school teacher training colleges in Masvingo province of Zimbabwe in producing teachers with positive attitudes towards educating children with disabilities in the ordinary classroom. In the process, the effectiveness of the skills and competencies being used and problems being encountered by the student teachers were also investigated. A combination of qualitative and quantitative methodology was used. Data were gathered from a purposive randomly selected sample of a total of ninety second year students on teaching practice. These students were teaching pupils with disabilities in six schools in Masvingo district. The tools for gathering data were questionnaires, interviews, observation and document analysis The findings indicated that students 'attitudes were still largely negative. It was also revealed that skills and competencies used were not effective enough to make teaching and learning enjoyable and effective for both the student teachers and the pupils with special needs. The major areas of concern were; attitudes, curriculum adaptation, lack of suitable skills and methods, assessment and time management. In short, it was established that at present teacher training colleges were not preparing students adequately to handle inclusive classes. It is recommended that primary teacher training colleges put in place comprehensive syllabi which can equip students adequately with skills and competencies required for teaching inclusive classes.
\end{abstract}

\section{Background to the study}

Motivation for this investigation follows the Zimbabwe Education Act of (1987) which states that, "Every child in Zimbabwe should have a right to school education." The act refers to the children with disabilities as well. Further, by signing the Salamanca World Conference declaration on special needs education, UNESCO (1987), Zimbabwe embraced the principles of inclusion for those with specific education needs which aim at achieving education for all in the least restrictive environment.

Research by Dakwa (1983), Chireshe and Mapfumo (2002) and Makoni (2003) recommend that a special education component be incorporated in the teacher education curriculum so that teachers can accept and meaningfully help children with special needs in the inclusive classroom. Although the researchers do not indicate the manner in which such a special education component should be incorporated, their recommendation seems to imply that teachers lacked positive attitudes and skills teaching children with special needs.

UNESCO (2002) notes that one of the major weaknesses with the Zimbabwean education system since precolonial times has been the emphasis on producing teachers who could teach the learner of at least average intellectual ability while neglecting the development of a versatile teacher competent enough to meet the varied special needs of learners in regular classrooms.

Admittedly, some teachers are doing Bachelor of Education (Special Needs Education) but this definitely does not answer the need, as most classes have about one or more pupils with special needs. Most teachers who teach regular classes, according to recommendations cited above, are inadequately trained to offer meaningful tuition to children with special needs.

It is in the context highlighted above that this investigation sought to verify whether the recommendations of the said researchers and government policy are bearing fruit considering that special needs education has been recently introduced in the training of student teachers destined to teach in the regular classroom. It should be noted however that different colleges implement training in special needs variously. At the moment it is not a 'stand alone' subject but is incorporated in other subjects as different institutions see fit. This makes it necessary to ascertain the effectiveness of teachers' colleges in this area.

\section{Theoratical Framework}

This paper leans on the philosophy of normalization, which refers to the use of progressively more normal settings and procedures to establish and /or maintain personal behaviours which are culturally as normal as possible (Wolfensberger in Herward and Orlansky 1988; Slavin 2002). The philosophy holds that persons 
with handicaps should be both physically and socially integrated into the mainstream of society to the greatest extent possible, regardless of the degree or type of disability. This allows each handicapped person`s life to be as normal as possible in all aspects including residence, schooling, work, recreational activities, and overall independence. In normalization similarities rather than differences between the handicapped and the nonhandicapped are emphasized.

Unlike practice in the era between 1800 - 1900 where those with disabilities were institutionalised and kept out of the public eye and the period from the 1960s which saw the children with disabilities integrated in schools, inclusive education embraced these children in the regular classroom where they learn with their nondisabled peers. Of importance to note is that the issues of concern in the principle of normalization relate very closely with those of inclusive education which, according to ( Donald, Lazarus and Lolwana 2010) ensures optimal accommodation and inclusion of the full variety of educational needs in a single education system.

To narrow down from the broad framework based on the philosophy of normalisation, the researcher also leaned on Vygotsky's (1978) socio-cultural theory of cognitive development. Vygotsky's (1978) socio-cultural theory maintains that how we think is a function of both social and cultural forces (Snowman, McCown and Biehler 2009).According the socio-cultural theory then, parents and schools shape children's (both disabled and nondisabled) thought processes to reflect that which culture values. In line with this perspective inclusive education requires that the disabled children attend their neighbourhood school together with their non-disabled brothers and sisters, rather than attend secluded institutions away from their own community and culture ( Donald, Lazarus and Lolwana 2010; Dolmage 1996)

According to Vygotsky's view, people's knowledge of the world and the development of higher mental functions are mediated by interaction with the material world and other more competent human beings. So as children with specific needs learn together with their non -disabled peers in the regular classroom they develop higher mental functions as they interact with their peers teachers. This social interaction between the teacher and all pupils in the inclusive classroom is important for the development of higher mental functions.

Vygotsky's concept of Zone of Proximal Development (ZDP), which is defined as the dynamic region of sensitivity in which the child's mental functions develop in joint problem solving with more skilled members of their society (Elliot,Travers, Kratochwill, and Cook 2000), is crucial to successful learning in all pupils, especially for the those with special needs. Flem, Moen, and Gudmundsdottier (2000) note that as the child's cognitive development occurs through participation in activities slightly beyond its competence, the task of the more skilled person, in this case the teacher, is to structure and model the learning situation. Working through the ZDP therefore requires that both the teacher and the pupil are active and responsible in the learning and teaching activities. The idea is that as the child's expertise grows, it takes on more and more responsibility for managing tasks and gradually come to perform the task alone. Scaffolding, a term used by Wood, Bruner and Ross in Berger (2000) to refer to assistance offered in the ZDP, sees the child develop from other-regulation to self-regulation (Flem et al 2000). In other words, through this assistance the children gain mastery over their behaviour.

This paper leans on this theory (socio-cultural) to understand and examine the teaching of pupils with specific needs and determine the extent to which colleges prepare student teachers to facilitate social and academic development of all children in the inclusive class.

\section{Research Design}

\section{Methodology}

The study adopted both qualitative and quantitative research designs. The use of the two designs promoted triangulation, a practice which Gray (2004) notes as not only assisting data triangulation but also helps balance out any of the potential weaknesses in each data collection method. Consistent with the idea of triangulation, the researcher used questionnaires, interviews and observation as tools of data collection.

\section{Sampling}

Purposive random sampling was used to select the sample for the research. Ninety nine second year students from the three primary teachers' training colleges in Masvingo province were chosen, thirty three from each college. These had received some form of special needs education variously at their colleges as stated earlier in the background to the study. They were also selected on the qualification that they were teaching pupils with special needs in their regular classrooms.

\section{Research Instruments}

The questionnaire, interview, observation and document analysis were the tools used in data collection. The purpose of using directly administered questionnaire was to capture information on students' perceptions, attitudes and feelings as well as competencies they had in teaching children with special needs in the ordinary classroom. The semi-structured interviews were administered to (9) nine students to elicit data on their 
preferences regarding the education of children with specific needs - whether they should be educated separately or together with their peers in the regular classroom and the skills and competencies they were using in teaching the inclusive classes.

Naturalistic observation yielded information on how the student teachers managed the teaching/learning situation regarding, the handling of behaviour problems, the methods and techniques used and the interaction patterns in the classroom.

Document analysis was used to collect data on attitudes as evidenced by how teachers marked, methods and techniques used in teaching (plan books) and progress the pupils were making. Such information was accessed by studying the record books and pupils' books. College syllabi were also scrutinised. Checklists were used to ensure consistence in data collection.

\section{Results}

Results of the study are organised in terms of the major issues investigated, namely;

- Attitudes and feelings of students toward inclusion;

- Skills and competencies used;

- Problems encountered by the students in teaching inclusive classes.

\section{Attitudes and feelings}

Data from questionnaire was analysed using and chi-square tests. The chi-square test was used to establish the significance of statistical differences in the non-parametric data obtained (Best and Kahn 1993). Qualitative data was presented in descriptive form.

Table 1: Students' views on inclusive education

\begin{tabular}{|c|c|c|c|c|c|c|}
\hline Response & \multicolumn{3}{|c|}{ Institution } & $\begin{array}{l}\mathrm{X} 2 \\
\mathrm{Cal}\end{array}$ & $\begin{array}{l}\mathrm{X} 2 \\
\text { Crit }\end{array}$ & $\begin{array}{l}\text { Significance } \\
\text { Level }\end{array}$ \\
\hline & $\begin{array}{c}A \\
\text { No=30 } \\
\%\end{array}$ & $\begin{array}{c}B \\
N_{0}=30 \\
\%\end{array}$ & $\begin{array}{c}\mathrm{C} \\
\mathrm{No}=30 \\
\%\end{array}$ & 42.577 & 6.00 & Significant \\
\hline YES & 73 & 27 & 47 & & & \\
\hline $\mathrm{NO}$ & 27 & 73 & 53 & & & \\
\hline
\end{tabular}

$\mathrm{df}=2$

Cal x2 (42.577) $>$ Crit x2 (6.00)

There is a significant difference in opinions among students from different institutions regarding the issue on whether children with disabilities should be educated in the general classroom or not.

Data in Table 1 above shows that the three colleges differ in their feelings towards inclusive education. A possible explanation for the differences could be that the thrust in teaching SNE differed in colleges. As indicated earlier, colleges approached the teaching of SNE as they felt fit. Results from content analysis of college syllabi offer a sound explanation to the differences in opinion. Institution A, which was the only one with a relatively high response of $73 \%$ in favour of inclusive education, was found to have the most comprehensive syllabus as compared to the other two. However, institution B with $27 \%$ positive response has a more comprehensive syllabus than institution $\mathrm{C}$ which recorded $47 \%$ positive response. The results of institutions B and C appear to be illogical in that one would think that college B with a more comprehensive syllabus would have a higher positive response than college $\mathrm{C}$. This anomalous situation could be explained by the fact that institution B shares the same campus with a special school, so they could have been led by this to believe that separate education was better.

Data from interviews and observation on student attitudes confirmed the results from the questionnaire, that attitudes towards inclusion were still largely negative among student teachers .Out of the nine (9) students interviewed $67 \%$ were against inclusive education.

Documents revealed that the pupils with disabilities were neglected as their needs were not addressed in planning - focus was on the average child. Evidence from pupils' written exercise books that were scrutinised showed that teachers neglected the work of children with specific needs. Out of the twenty exercise books that were looked at $55 \%$ had exercises that were either unmarked or simply underlined to indicate that the teacher had seen the work. There was no evidence that the teacher made efforts to assist the children. The written work given was clearly above their level. All this indicates the students' negative attitudes towards the children with disabilities, especially the slow learners.

Among students who responded in favour of inclusion, the following reasons were given in order of their popularity; 
$>$ To avoid stigmatisation

$>$ To promote interaction and assistance by non disabled peers

$>$ To prepare for meaningful functioning in society.

The following reasons were given by students who responded against inclusion in their order of popularity;

$>$ The disabled may feel out of place (in the regular classroom)

$>$ Some of their needs cannot be met in the regular classroom

$>$ The disabled need more time and attention

$>$ They disturb those who are non-disabled

The reasons given above confirm that a knowledge of the rationale for inclusion promotes positive attitudes towards inclusive education. Also, the positive reasons given for inclusive education are in agreement with the philosophy of normalization which espouses the use of progressively more normal settings and procedures to establish and/ or maintain personal behaviours which are culturally as normal as possible (Wolfensberger in Herward and Orlansky 1998).

\section{Skills and Competencies Used by Students to Enhance Pupil's Social Development}

$55 \%$ of student teachers indicated that they did nothing to socially prepare their non-disabled pupils to learn with pupils with special needs in advance. Further questioning on how non- disabled pupils related to those with disabilities, $60 \%$ of the respondents revealed that the children without disabilities often laughed at and teased their peers with disabilities when they did something wrong.

Perhaps if preparation was made proactively a better classroom community in which all pupils thrive could have been created. Gearheart et al (1992) and Cook, Tessier and Klein (1998) suggest that adequate preparation has to be made in order to create a positive community for all learners.

On the issue of behaviour control, $75 \%$ of the interviewees said that they used verbal reprimand, $8 \%$ taught moral values and $17 \%$ explained to pupils that they should not laugh at their disabled peers. Those students who taught pupils with psychological problems such as withdrawal and aggression indicated that they experienced problems because they did not know what to do. Although they (students) acknowledged the importance of giving rules, $50 \%$ complained that rules would often be broken.

Results from the researcher's observation during lessons reveal that a while after being reprimanded pupils would revert to misbehaviour and rules were also often broken by those with special needs as well as those without. This observation concurs with the results of the interviews above.

Heward and Orlansky (1988) and Soodak (2003) suggest that the starting point for effective behaviour change is to establish the deficits and the root causes before making a plan of action to eradicate and replace the undesired behaviour.

\section{Skills and Competencies Used to Enhance Academic Progress}

Interviews revealed that $83 \%$ of the students sometimes used the modelling technique to assist pupils with special needs and the rest said they rarely used it. However, both those who sometimes used it and those who rarely used it concurred that they never planned to use the technique, they only used it when need arose. $75 \%$ intimated that the technique was not very helpful since, "Even if I do (use modelling) they do not remember what I model, they have a short memory" said one student. Confirming the results of the interview on the use of modelling as a teaching strategy, observation showed that the instances modelling was used there was insufficient follow up, no supervised practise of modelled behaviour and there was no feedback on how well the children with disabilities were imitating the models.

According to the data at hand, modelling as a teaching technique was viewed a failure by student teachers most probably because it was not well structured since it was not planned for. These results are not surprising since, according to Milburn and Cartledge in Heward and Orlansky (1988) modelling can only be successful if the necessary procedure, which is, exposure of the child to the model of imitation, eliciting an imitative response, providing feedback about the correctness of the response and structuring opportunities for practice is not followed. In view of results and the discussion, children with special needs are denied opportunities to be guided by more competent peers, which Vygotsky sees as important in his socio-cultural theory. According to Vygotsky scaffolding entails support for learning in the form of clues, reminders, encouragement, breaking the problem down into steps or anything else that allows the student to grow in independence (Slavin 2002).

The interview also showed that $83 \%$ of the student teachers were opposed to the idea of peer tutoring "... because it slows down their (competent pupils) progress, they need to go on with their own work" said one student. Only $17 \%$ indicated that they used peer tutoring, but with reservation, saying that "Peer -tutoring should not be done very much - they (competent pupils) need to go on with their work. They can do it (peer tutoring) in the afternoon." Although one would be tempted to agree with the latter perception, research has found that both the slow learner and the peer tutor benefit (Rayan and Cooper 1995; Jennifer, ehow.com). 
Observation notes revealed that, cooperative learning was not being used in its real sense, what students referred to as cooperative learning was ordinary group work in which pupils had no special tasks assigned to them. This misconception on the part of the students also indicates that SNE is not yet adequately covered at some teachers' colleges.

Mixed ability grouping was used in all classes that were observed and reasons given where quite plausible, for example, to avoid labelling and to allow pupils to assist each other. While this finding confirms Kruger and Van Schslwky's (1977) observation that homogenous groups are unpopular in modern time and are not encouraged since they may give rise to labelling, it contradicts the ideology of inclusion which entitles pupils to a differentiated education. Lemleck (1988) asserts that ability grouping is important as well since it facilitates differentiation and group teaching especially in subjects such as Reading and Mathematics. The use of ability grouping only may therefore suggest that while pupils were being 'protected' from labelling, they were also being subjected to content that was inappropriate for their level of ability. Since there are advantages and disadvantages to both ways of grouping it would be advisable to use them when it is appropriate.

Results from observation also revealed the following;

$>$ Teachers rarely gave assistance to slow learners

$>$ Participation by slow learners was rare (teachers rarely called on them)

$>$ Slow learners did not approach teachers to ask for help

$>$ Slow learners engaged in off task behaviour during group work

$>$ Teachers rarely checked on the understanding of those with special needs

$>$ Slow learners were addressed when they made noise otherwise they were largely unattended to

$>$ Record books showed that teaching content focussed on the average child

$>$ Norm referenced tests were always used

$>$ Comments given in weak pupils were "Finish your work" or "Be serious" and sometimes the work was not even marked. Since they performed poorly most of the time, they never got encouraging comments

$>$ There was no evidence of individual education programmes (IEP)

All practices listed above show that pupils with special needs especially those who are mentally challenged are not given adequate assistance in the regular classes. This suggests that students being churned out by primary teacher training are not sufficiently prepared in this regard.

\section{Problems Being Experienced By Student Teachers in the Inclusive Class}

Table 2. Shows students' responses to the questionnaire on problems they are encountering in teaching inclusive classes.

Table 2 Problems faced by student teachers in teaching inclusive classes $\mathrm{N}=90$

\begin{tabular}{|c|c|c|c|c|c|c|c|c|}
\hline \multirow{3}{*}{ PROBLEMS } & \multicolumn{8}{|c|}{ RESPONSES BY INSTITUTION } \\
\hline & \multicolumn{2}{|c|}{ A. $\quad \mathrm{N}=30$} & \multicolumn{2}{|c|}{ B. $\quad \mathrm{N}=30$} & \multicolumn{2}{|c|}{ C. $\quad \mathrm{N}=30$} & \multicolumn{2}{|c|}{ TOTAL } \\
\hline & $\mathrm{F}$ & $\%$ & $\mathrm{~F}$ & $\%$ & $\mathrm{f}$ & $\%$ & $\mathrm{~F}$ & $\%$ \\
\hline $\begin{array}{l}\text { Lack of techniques } \\
\text { and methods }\end{array}$ & 21 & 70 & 23 & 77 & 21 & 70 & 65 & 72 \\
\hline $\begin{array}{l}\text { Lack of knowledge } \\
\text { On different disabilities }\end{array}$ & 17 & 56 & 15 & 30 & 19 & 63 & 51 & 57 \\
\hline No skills in using equipment & 14 & 45 & 15 & 50 & 12 & 40 & 41 & 46 \\
\hline Time management & 23 & 77 & 25 & 83 & 21 & 70 & 69 & 77 \\
\hline
\end{tabular}

Table 2 reflects problems that are faced by students in institutions A, B and C in the inclusive classrooms they teach. The highest problem experienced by all institutions was that of time management with $77 \%$, followed by, lack of techniques with a total percentage of $72 \%$, then lack of knowledge of different disabilities with $57 \%$ and lowest problem recorded was, lack of skills in using equipment with $46 \%$.

An interview carried out on nine students had results similar to those the questionnaire. $83 \%$ indicated that they experienced shortage time of to cater for all pupils meaningfully. The following were recurrent problems indicated in the interviews;

$>$ "I need methods to help them (children with disabilities) understand and remember"

$>$ "I have problems of shortage of time, I cannot cater for all pupils, the slow ones hardly make any progress"

$>$ "I do not know how to deal with the pupils (disabled). I prefer that they go to the special class where they can get enough help." 
This again means that students lack the preparedness needed to teach in inclusive settings. The students' inadequacy has serious repercussions for both the pupils and the student teachers themselves. The response " I do not know how to deal with the pupils. I prefer that they go to the special class where they get enough help" shows that the student was frustrated by the problems she was encountering for which she could not find solutions. A study carried out by Chimedza and Peters (2001) revealed that students who were unable to handle problems of children with special needs felt that their self confidence and integrity were undermined. Mushoriwa (2002) notes that where teachers fail to properly and adequately adjust the materials and methods for such children their handicaps became even more visible, making the children more stupid before their peers

\section{Conclusion}

The findings revealed and discussed in this report provide ample indications of the need for colleges to offer more comprehensive training in special needs education to optimise and build a sense of belonging and well-being in each learner.

\section{References}

[1]. Berger, K. S.(2000) The Developing Person :Through Chilhood. New York:Worth Publishers.

[2]. Best, J.W. and Khan, J.V.(1993) Research in Education. Boston: Allyn and Bacon.

[3]. Chimedza, R. and Peters, S. (2001) Disability and Special Needs Education In an African Context. Zimbabwe Bulletin of Teacher Education.

[4]. Chireshe, R. and Mapfumo, J. (2002) Focus on the Slow Learner :The Zimbabwe Journal of Education.

[5]. Cohen, L. and Manion, L. (2007) Research in Education. London: Routeledge.

[6]. Cook, R. E; Tessier, A. and Klein, M. D. (1996) Adopting Early Childhood Curricula for Chidren in Inclusive Settings. New Jersey: Prentice Hall.

[7]. Dakwa, F.E .(1993) An Investigation into the Understanding of Visually Handicapped Children in Four Ordinary Schools. Unpublished M.Ed. Dissertation: University of Whales.

[8]. Dolmage, M. (1996) Building Inclusive Schools-ConsistentThemes and Ideas. http://www.community living Ontario.co/schools/themes.htm/

[9]. Donald, D; Lazarus, S.and Lolwana, P.(2010) Educational Psychology in Social Context, Ecosystemic Applications in Southern Africa, Cape Town :Oxford University Press Southern Africa (Pty) Ltd.

[10]. Flem, A; Moen, T. and Gudmundsdottier, S. (2000) Towards Inclusive Schools :A Study of How a Teacher can Facilitate Differential Instruction. http:leeds.ac.uk/edu.col/documents/00001570.htm

[11]. Gearheart,B. R.; Weisham, M. W. and Gearheart,J. (1992) The Axceptional Student in the Regular Classroom. London: Merrill.

[12]. Gray, D.E.(2004) Doing Research In The Real World. London: Sage.

[13]. Herward,W. L. and Orlansky, O. J.(1994) Exceptional Children: Introduction to Special Needs Education. Boston: Allyn and Bacon.

[14]. Kruger, A.G.and Van Schalwky, O. J. (1997) Classroom Management. Pretoria: Van Schaik Publishers.

[15]. Makoni, P.E.T. (2003) Specialist Teachers' Perceptions of Current Practice in Integrating Pupils with Disabilities in the Mainstream. Zimbabwe Bulletin of Teacher Education vol,1(1)

[16]. Rayan,K. and Cooper, J. M. (1995) Those who can Teach, Boston: Houghton and Mifflin

[17]. Snowman, J; McCown, and Biehler, R. ((2011) Psychology Applied to Teaching, Boston: Houghton and Mifflin.

[18]. Soodak, L.C.(2003) Theory Into Practice: Classroom Management In Inclusive Settings. http://www.weac.org/resource/june96/speced.htm.

[19]. Elliot ,S.N; Travers, J.F ; Kratochwill, T.R. and Cook, J. L. (2000)Eductional Psychology: Effective Teaching Effective Learning. Madison:Brown and Benchmark.

[20]. UNESCO (1994) The Salmanca Statement and Framework on Special Needs Education. Paris:UNESCO

[21]. UNESCO (2002) Inclusive Education in Southern Africa- Responding to Diversity in Education, Harare: Jennifer, E. http://www.ehow.com/list 6599196 benefits of peer tutoring-elementary school(retrieved 09/2013) 